\title{
Eosinophilic gastritis: histopathological characterization and quantification of the normal gastric eosinophil content
}

\author{
Thida Lwin ${ }^{1}$, Shelby D Melton ${ }^{2,3}$ and Robert M Genta ${ }^{1,2,3}$ \\ ${ }^{1}$ Division of Gastrointestinal Pathology, Caris Research Institute, Caris Life Sciences, Irving, TX, USA; \\ ${ }^{2}$ Department of Pathology, Veterans Affairs North Texas Health Care System, Dallas, TX, USA and \\ ${ }^{3}$ Department of Pathology, University of Texas Southwestern Medical Center, Dallas, TX, USA
}

\begin{abstract}
There is limited information about normal eosinophil counts in the gastric mucosa. The purpose of this study was to evaluate the histopathology of 60 patients whose biopsies showed increased eosinophils in the gastric mucosa. We also investigated the eosinophil content in gastric biopsies from normal controls (matched for age, sex, and zip code), from patients with Helicobacter pylori gastritis, and patients with Crohn's disease. Eosinophils were counted in five random high-power fields (HPFs) and reported in eosinophils $/ \mathrm{mm}^{2}$. Involvement of the muscularis mucosae or submucosa, sheets of eosinophils, and infiltration of the gastric epithelium were also evaluated. The median eosinophil count in the study patients was 539 eosinophils $/ \mathrm{mm}^{2}$; mean $\pm S D=653 \pm 418$ eosinophils $/ \mathrm{mm}^{2}$; range 127-2108. Sheets of eosinophils were seen in 38 patients, 27 showed involvement of the muscularis mucosae or submucosa. There were 7 patients without epithelial infiltration by eosinophils, whereas $\mathbf{3 4}$ were tallied as rare and 19 were scored as abundant. No study patient had no evidence of $H$. pylori. The mean eosinophil count for the 135 normal controls was $15.5 \pm 16.8$ SD eosinophils $/ \mathrm{mm}^{2}$ (range $0-110$ ); in the 93 controls with $H$. pylori gastritis the mean eosinophil count was $25 \pm 32.6 \mathrm{SD}$ eosinophils $/ \mathrm{mm}^{2}$ (range 0-219); and for the 53 controls with Crohn's disease it was $31.4 \pm 44.4$ SD eosinophils $/ \mathrm{mm}^{2}$ (range 0-203). There were no significant differences between the counts in biopsies from the antrum and corpus, and no significant variations by age, geographic location, or season. This study confirms that, in the United States population, the normal gastric eosinophilic counts are usually $<38$ eosinophils $/ \mathrm{mm}^{2}$. We recommend 'histological eosinophilic gastritis' for the diagnosis of gastric biopsies that show an average density $\geq 127$ eosinophils $/ \mathrm{mm}^{2}$ (or $\geq 30$ eosinophils per HPF) in at least five HPFs in the absence of known associated causes of eosinophilia.

Modern Pathology (2011) 24, 556-563; doi:10.1038/modpathol.2010.221; published online 17 December 2010
\end{abstract}

Keywords: eosinophil; eosinophilic gastritis; eosinophilic gastroenteritis; gastric biopsy; normal eosinophil count; stomach

When confronted with a biopsy showing 'greater than normal' numbers of eosinophils in the gastric mucosa, a pathologist has limited available resources that can help decide whether or how to report this finding: non-standardized descriptions found in case reports, ${ }^{1-5}$ or brief sections in textbooks. ${ }^{6}$ Surprisingly, the normal eosinophilic content in the lamina propria of the gastric mucosa has

Correspondence: Dr RM Genta, MD, Division of Gastrointestinal Pathology, Caris Research Institute, Caris Life Sciences, 6655 North MacArthur Boulevard, Irving, TX 75039, USA.

E-mail: robert.genta@utsouthwestern.edu

Received 10 August 2010; revised 20 October 2010; accepted 20 October 2010; published online 17 December 2010 rarely been investigated. ${ }^{7-9}$ No consensus exists on specific limits for normality and, consequently, there are no guidelines as to what constitutes an excessive number of eosinophils in gastric mucosal biopsies. Although acknowledging this uncertainty, the updated Sydney system specifically stated that intraepithelial eosinophils must always be viewed as abnormal. ${ }^{10}$

Increased numbers of eosinophils in the lamina propria have been reported after eradication therapy for Helicobacter pylori, ${ }^{11}$ in reactive gastropathy caused by certain drugs, ${ }^{12}$ and in focal responses to tissueinvading parasites, particularly Anisakis spp. larvae. ${ }^{13}$ Increased gastric eosinophils can also be identified in patients with the rare eosinophil-associated 
gastrointestinal disorders. ${ }^{14,15}$ In these situations, it has been suggested that the term 'mucosal eosinophilia' be used when the increase in eosinophils is limited to the lamina propria, reserving the designation of 'eosinophilic gastritis' for cases in which eosinophils infiltrate the surface or foveolar epithelium, the muscularis mucosae or the submucosa, or other mucosal damage (such as foveolar hyperplasia, architectural distortion, significant chronic, or active inflammation) is present. ${ }^{16}$ The purpose of this study was to characterize the histopathology of gastric biopsies with increased eosinophils. We then aimed to synthesize these findings into a diagnosis of 'histological eosinophilic gastritis.' In addition, we sought to determine the normal range of gastric mucosal eosinophils in a geographically varied North American population.

\section{Materials and methods}

\section{Study Setting}

This study was conducted at Caris Life Sciences, a specialized gastrointestinal laboratory receiving specimens from gastroenterologists operating in private outpatient endoscopy centers across the United States. The study was approved by the Caris Institutional Review Board. Because all data in this study were collected entirely by reviewing existing de-identified records, no direct contact with either patients or providers was involved, and no individual information is revealed in any form, this study was considered exempt from the need for informed consent from participants.

\section{Patients and Controls}

We analyzed electronic data from the Caris database, which includes demographic and clinical information for each patient, a summary of the endoscopic findings or the entire endoscopic report, the site of origin of each specimen, and the histopathology report for each biopsy. To identify the records for eligible patients, we extracted data for all patients who had at least one gastric biopsy submitted to Caris between 1 January 2008 and 31 December 2009. By electronically analyzing the histopathology reports and using additional search terms and Boolean logic in Visual Basic for Applications, we collected all gastric biopsies in which either the diagnostic line of the pathology report or the comment mentioned 'eosinophils.' For the Boolean search we used all variations of the root 'eosinoph*,' and reviewed manually reports that appeared to be of interest. To identify the normal gastric mucosal eosinophil content, we selected two to three normal control subjects for each study patient; to account for potential reported variations, ${ }^{17,18}$ normal controls were matched for age ( \pm 1 year for children and \pm 2 years for adults), sex, and zip code, and had histologically unremarkable gastric biopsies. In addition, we counted gastric mucosal eosinophils in a set of 93 sex- and age-matched patients with H. pylori infection confirmed by immunohistochemical staining, and in 53 sex- and age-matched patients with chronic active ileitis or colitis and a clinical history or suspicion of Crohn's disease. Patients with focally enhanced gastritis were excluded.

\section{Histopathology}

Hematoxylin and eosin stained gastric biopsy slides from all study patients and controls were reviewed. Eosinophils in the lamina propria were counted in five random high-power fields (HPFs) ${ }^{9}$ per biopsy specimen using an Olympus BX41 microscope with a UPlan FLN 40X/0.75 lens and an FN 22 eyepiece; this 'HPF' includes an area on the slide of $0.237 \mathrm{~mm}^{2}$. The density of eosinophils was then reported in eosinophil $/ \mathrm{mm}^{2}$. Involvement of the muscularis mucosae or submucosa, and sheets of eosinophils were noted as present or absent. Infiltration of the gastric epithelium was scored on a scale of 0-2 (absent, mild or rare, and marked or abundant). All specimens were also stained with the immunohistochemical stain for $H$. pylori (Cell Marque, Rocklin, CA, USA).

\section{Results}

\section{Patients}

A total of 248307 unique patients had gastric biopsy specimens diagnosed in our laboratory during the 2 years of the study. Increased gastric mucosal eosinophils were mentioned in the histopathology reports of 71 patients. After reviewing the slides, 11 of these patients were found to have patchy or minimal eosinophils in the lamina propria with no epithelial involvement, and were not considered diagnostically appropriate for inclusion. Thus, there remained 60 study patients, for which 135 appropriately matched controls were selected. Demographic information on the study patients is found in Table 1. There were 10 children (2 girls and 8

Table 1 Demographics

\begin{tabular}{lc}
\hline & Total \\
\hline Adults & 50 \\
Women & 32 \\
Men & 18 \\
Median age & 55.5 \\
Age range & $18-83$ \\
Children & 10 \\
Girls & 2 \\
Boys & 8 \\
Median age & 9 \\
Age range & $4-14$ \\
\hline
\end{tabular}


Table 2 Clinical indications for esophagoduodenoscopy and gastroscopic findings

\begin{tabular}{|c|c|c|}
\hline \multicolumn{3}{|c|}{ Clinical presentation } \\
\hline & $\begin{array}{c}\text { Children } \\
(\mathrm{n}=10, \%)\end{array}$ & $\begin{array}{c}\text { Adults } \\
(\mathrm{n}=50, \%)\end{array}$ \\
\hline Epigastric pain & $5(40)$ & $15(30)$ \\
\hline GERD & $2(20)$ & $6(12)$ \\
\hline Dysphagia & $1(10)$ & $6(12)$ \\
\hline Vomiting & $1(10)$ & $5(10)$ \\
\hline $\begin{array}{l}\text { Follow-up of eosinophilic } \\
\text { esophagitis }\end{array}$ & $1(10)$ & - \\
\hline Dyspepsia & - & $3(6)$ \\
\hline Melena & - & $3(6)$ \\
\hline Weight loss & - & $2(4)$ \\
\hline Anemia & - & $2(4)$ \\
\hline Hematemesis & - & $1(2)$ \\
\hline Nausea & - & $1(2)$ \\
\hline $\begin{array}{l}\text { Follow-up of ulcer, gastritis and } \\
\text { gastric adenoma }\end{array}$ & - & $6(12)$ \\
\hline \multicolumn{3}{|c|}{ Endoscopic impressions } \\
\hline Normal stomach & $6(60)$ & $11(22)$ \\
\hline Gastritis, erythema & $3(30)$ & $23(46)$ \\
\hline Gastric ulcers/erosions & $1(10)$ & $10(20)$ \\
\hline Polyps or mass & - & $2(4)$ \\
\hline Giant folds & - & $1(2)$ \\
\hline Nodular mucosa & - & $1(2)$ \\
\hline Gastropathy & - & $1(2)$ \\
\hline Not reported & - & $1(2)$ \\
\hline
\end{tabular}

boys, aged 4 to 14 ) and 50 adults (32 women; $64.0 \%$ ). The median age of all patients was 50 (range 4-83). The clinical indications leading to esophagogastroduodenoscopy and gastroscopic findings in study patients are detailed in Table 2. Epigastric pain was the most common presenting manifestation in both adults and children, followed by reflux disease and dysphagia. Endoscopically, the most common findings were a normal stomach or erythema and gastritis, with or without erosions. The clinical and histopathological findings in each of the 60 study patients are depicted in Table 3 .

\section{Histopathological Features of Eosinophilic Gastritis}

The histological findings in gastric biopsies of study patients are summarized in Table 4. The median eosinophil density was $539 / \mathrm{mm}^{2}$; mean $\pm \mathrm{SD}=$ $653 \pm 418 / \mathrm{mm}^{2}$; range $127-2108$. Figure 1 shows an antral biopsy with markedly increased eosinophils. All patients had eosinophilic clusters scattered in the lamina propria. Sheets of eosinophils (Figure 2) were seen in the biopsies from $38(63.3 \%)$ patients. The gastric epithelium was infiltrated by eosinophils in $53(88.3 \%)$ patients (Figure 3); the epithelial involvement was scored as abundant in 19 cases and rare in 34 . In contrast to neutrophilic processes (eg, as in H. pylori infection), eosinophils tended to surround the foveolae and infiltrate their epithelium, but virtually never spilled into the lumen to form eosinophilic 'pit abscesses' (Figure 4). Muscularis mucosae or submucosal tissue involvement was noted in 27 patients (Figure 5). Intestinal metaplasia was seen in the biopsies of two patients. H. pylori organisms were not detected by immunohistochemistry in any of the patients.

\section{Gastric Eosinophils in Controls}

Figures $6 \mathrm{a}$ and $\mathrm{b}$ illustrate the eosinophilic content typically found in the antrum and corpus of control subjects. The mean eosinophil count for the 135 control patients (84 women, or $62.2 \%$; median age 50 years, range 4-81) was $15.5 \pm 16.8$ SD eosinophils $/ \mathrm{mm}^{2}$ (range $0-110$ ). Only one of the controls (a 56-year-old woman of Japanese origin) had a mean count of 110 eosinophils $/ \mathrm{mm}^{2}$. All other controls averaged fewer than 55 eosinophils $/ \mathrm{mm}^{2}$. There were no significant differences between the counts in biopsies from the antrum and corpus, and no significant variation by either age or geographic location (data not shown). The median density of eosinophils in age- and sex-matched patients with $H$. pylori infection or Crohn's disease was lower than in normal controls (15.8 and 9.5 eosinophils/ $\mathrm{mm}^{2}$, respectively, vs 25 eosinophils $/ \mathrm{mm}^{2}$ in subjects with a normal stomach). However, both mean density and standard deviation were higher, reflecting the presence of a few patients with elevated counts (up to 203-219 eosinophils $/ \mathrm{mm}^{2}$ ) in each of these two groups.

\section{Histopathological Findings in other Parts of the Gastrointestinal Tract}

Of 23 patients with esophageal biopsies, 14 met the histological criteria for eosinophilic esophagitis; $;^{19}$ of 18 patients with concurrent duodenal biopsies two had increased eosinophils. None of the three patients with colonic biopsies had mucosal eosinophilia.

\section{Discussion}

An increased eosinophil count in gastric mucosal biopsies represents a rare and often baffling finding. One of the aims of our study was to identify a set of histological features that could serve as a foundation for the development of diagnostic criteria for eosinophilic gastritis. As the normal content of eosinophils in the stomach has not been thoroughly investigated, we first determined the normal eosinophil counts in the antrum and corpus of subjects with a normal stomach. In the Kalixanda study, Talley et $a l^{9}$ found a mean peak eosinophil count of $12 / 5$ HPF in biopsies from the cardia, body, and antrum of asymptomatic adult volunteers from northern Sweden. In 19 children from Ohio, whose gastric biopsies had been previously reported as 
Table 3 Demographic, clinical, and histopathologic findings in each of the 60 patients with eosinophilic gastritis

\begin{tabular}{|c|c|c|c|c|c|c|c|c|c|c|c|}
\hline Age & Sex & State & $\begin{array}{l}\text { Month of } \\
\text { Procedure }\end{array}$ & $\begin{array}{l}\text { Clinical } \\
\text { Presentation }\end{array}$ & $\begin{array}{l}\text { Endoscopic } \\
\text { appearance }\end{array}$ & $\begin{array}{l}\text { Gastric } \\
\text { site }(s)\end{array}$ & Eosinophils $/ \mathrm{mm}^{2}$ & $\begin{array}{l}\text { Intraepithelial } \\
\text { eosinophils }\end{array}$ & $\begin{array}{l}\text { Eosinophil } \\
\text { sheets }\end{array}$ & $\begin{array}{l}\text { Eosinophils in } \\
\text { muscularis mucosae }\end{array}$ & \\
\hline 4 & $\mathrm{~F}$ & $\mathrm{TX}$ & February & Vomiting & Normal & $\mathrm{W}$ & 254 & 1 & - & - & \\
\hline 5 & $\mathrm{M}$ & $\mathrm{TX}$ & January & Pain & Normal & W & 320 & 0 & - & - & \\
\hline 5 & $\mathrm{M}$ & $\mathrm{TX}$ & December & Dysphagia & Normal & $\mathrm{W}$ & 539 & 1 & + & - & \\
\hline 8 & $\mathrm{~F}$ & $\mathrm{TX}$ & December & Pain & Normal & W & 270 & 1 & + & - & \\
\hline 9 & $\mathrm{M}$ & $\mathrm{TX}$ & January & GERD & Gastritis & A & 1180 & 2 & + & + & \\
\hline 9 & $\mathrm{M}$ & TX & August & GERD & Erythema & A & 888 & 2 & + & + & \\
\hline 10 & $\mathrm{M}$ & $\mathrm{TX}$ & January & Nausea, pain & Normal & A & 884 & 1 & - & - & \\
\hline 11 & $\mathrm{M}$ & TX & April & Pain & Normal & A & 802 & 0 & - & - & \\
\hline 13 & M & $\mathrm{TX}$ & April & F/U EoE & GUs & $\mathrm{C}$ & 675 & 1 & - & - & \\
\hline 14 & M & $\mathrm{TX}$ & October & Pain & Erythema & A & 418 & 1 & + & - & \\
\hline 18 & $\mathrm{~F}$ & $\mathrm{OH}$ & October & Vomiting & Normal & A & 463 & 1 & + & + & \\
\hline 23 & $\mathrm{~F}$ & AZ & November & Pain & Erosion & $\mathrm{A} / \mathrm{C}$ & 1645 & 2 & + & - & \\
\hline 24 & $\mathrm{~F}$ & GA & September & Dysphagia & Erosions & A & 1103 & 1 & - & - & \\
\hline 24 & $\mathrm{~F}$ & NY & November & Pain & Gastritis & A & 463 & 1 & - & + & \\
\hline 26 & $\mathrm{M}$ & AZ & March & Vomiting & Gastritis & $\mathrm{C}$ & 929 & 1 & + & - & \\
\hline 26 & $\mathrm{M}$ & $\mathrm{CA}$ & March & Pain & Normal & W & 209 & 2 & + & + & \\
\hline 28 & $\mathrm{M}$ & MD & January & Pain & Gastritis & $\mathrm{A}$ & 295 & 1 & - & - & \\
\hline 30 & $\mathrm{~F}$ & NC & October & Vomiting & Normal & $\mathrm{C}$ & 507 & 2 & + & - & \\
\hline 33 & $\mathrm{~F}$ & IL & November & $\mathrm{F} / \mathrm{U}$ adenoma & Polyps & $\mathrm{W}$ & 2108 & 1 & + & - & \\
\hline 36 & $\mathrm{M}$ & FL & April & Dysphagia & Gastritis & A & 254 & 1 & + & + & \\
\hline 37 & $\mathrm{~F}$ & KY & May & Pain & Erythema & $\mathrm{A} / \mathrm{C}$ & 209 & 1 & + & + & \\
\hline 39 & $\mathrm{~F}$ & NJ & Jul & GU & GU & $\mathrm{A} / \mathrm{C}$ & 463 & 1 & - & + & \\
\hline 40 & $\mathrm{~F}$ & CT & February & Pain & Erosion & W & 656 & 2 & + & + & \\
\hline 40 & $\mathrm{~F}$ & GA & November & Vomiting & Erosion & $\mathrm{A}$ & 380 & 1 & + & - & -1 \\
\hline 42 & $\mathrm{M}$ & NC & December & Dysphagia & Gastritis & $\mathrm{C}$ & 1052 & 0 & - & - & s. \\
\hline 47 & $\mathrm{M}$ & $\mathrm{TX}$ & May & GERD & Gastritis & W & 758 & 0 & - & - & 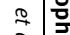 \\
\hline 48 & M & MD & May & Pain & Normal & $\mathrm{A}$ & 590 & 0 & + & + & 2 \\
\hline 49 & $\mathrm{~F}$ & LA & February & GERD & Normal & A & 336 & 1 & + & + & $\log _{\infty}$ \\
\hline 50 & $\mathrm{~F}$ & FL & Jun & Vomiting & Normal & $\mathrm{A} / \mathrm{C}$ & 1011 & 1 & - & + & $\stackrel{\mathscr{n}}{z}$ \\
\hline 50 & $\mathrm{~F}$ & PA & October & Nausea & Gastritis & $\mathrm{C}$ & 412 & 1 & + & - & $\overline{\bar{n}}$ \\
\hline 52 & $\mathrm{~F}$ & CA & August & GERD & Gastritis & W & 1011 & 2 & + & - & \\
\hline 53 & $\mathrm{M}$ & NC & February & Dysphagia & $\mathrm{F} / \mathrm{U}$ gastritis & $\mathrm{A}$ & 675 & 2 & + & + & \\
\hline 53 & $\mathrm{~F}$ & MA & October & F/U gastritis & Nodular & A & 1474 & 2 & + & + & \\
\hline 53 & $\mathrm{~F}$ & LA & May & Pain & Erosion & $\mathrm{W}$ & 758 & 2 & + & + & \\
\hline 55 & $\mathrm{~F}$ & OR & April & Anemia & Normal & $\mathrm{A}$ & 1645 & 2 & - & + & \\
\hline 56 & $\mathrm{~F}$ & GA & August & Weight loss & Giant folds & W & 2108 & 2 & + & + & \\
\hline 57 & $\mathrm{~F}$ & LA & January & Pain & Normal & $\mathrm{A}$ & 548 & 1 & + & + & \\
\hline 59 & $\mathrm{~F}$ & FL & October & Pain & Pyloric mass & A & 1011 & 2 & + & + & \\
\hline 60 & $\mathrm{~F}$ & MI & February & Anemia & $\mathrm{n} / \mathrm{a}$ & W & 675 & 2 & + & + & \\
\hline 60 & M & NY & April & Dysphagia & Gastritis & $\mathrm{A}$ & 802 & 2 & + & - & \\
\hline 62 & $\mathrm{~F}$ & MO & March & Melena & Normal & A & 508 & 1 & - & - & \\
\hline 62 & $\mathrm{~F}$ & MO & November & Pain & Erythema & A & 761 & 1 & + & + & \\
\hline 64 & $\mathrm{~F}$ & MA & Jun & Vomiting & Gastritis & A & 843 & 1 & + & - & \\
\hline 64 & $\mathrm{~F}$ & GA & April & Pain & Erythema & $\mathrm{C}$ & 656 & 1 & + & - & \\
\hline 65 & $\mathrm{M}$ & $\mathrm{OH}$ & February & F/U melena & GU & $\mathrm{A} / \mathrm{C}$ & 212 & 1 & - & - & \\
\hline 65 & $\mathrm{~F}$ & GA & March & Dyspepsia & Gastritis & W & 298 & 1 & - & - & \\
\hline 67 & $\mathrm{~F}$ & $\mathrm{OH}$ & May & Dyspepsia & Erythema & $\mathrm{A} / \mathrm{C}$ & 1180 & 2 & + & + & \\
\hline 68 & $\mathrm{M}$ & $\mathrm{OH}$ & December & GERD & Erosion & W & 380 & 2 & + & + & \\
\hline 71 & M & FL & August & GERD & Gastritis & A & 336 & 0 & - & - & \\
\hline
\end{tabular}




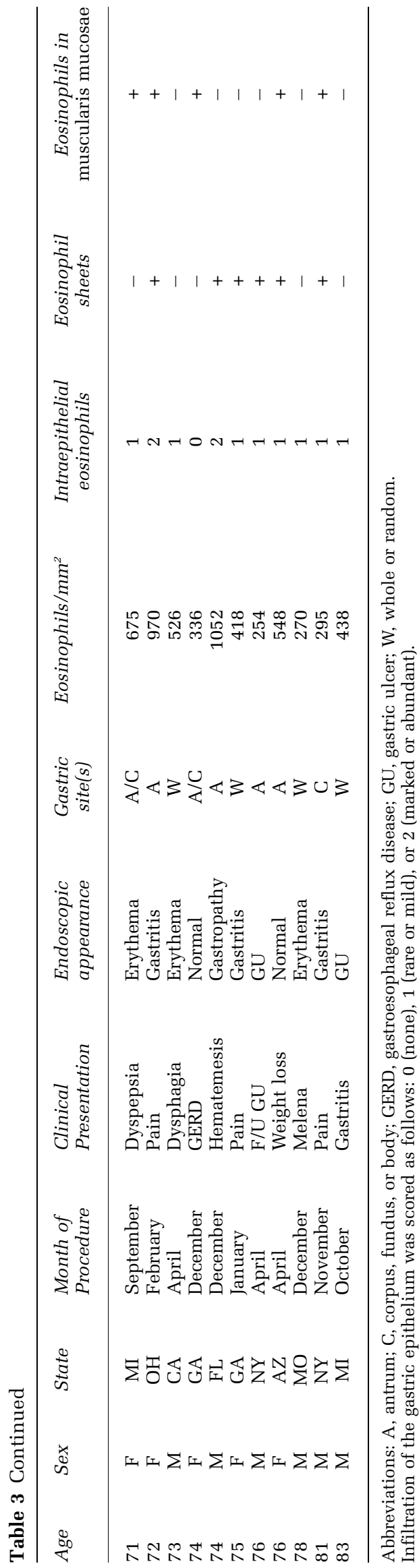

Table 4 Eosinophilic counts in study patients and controls

\begin{tabular}{lcccc}
\hline & $\begin{array}{c}\text { Study } \\
\text { patients }\end{array}$ & $\begin{array}{c}\text { Normal } \\
\text { controls }\end{array}$ & $\begin{array}{c}\text { Helicobacter } \\
\text { pylori gastritis } \\
\text { controls } \\
\mathrm{n}=93\end{array}$ & $\begin{array}{c}\text { Crohn's } \\
\text { disease } \\
\text { controls } \\
\mathrm{n}=53\end{array}$ \\
\hline $\mathrm{n}=135$ & $50(4-83)$ & $50(4-81)$ & $50(4-83)$ & $48(9-86)$ \\
$\begin{array}{l}\text { Women (\%) } \\
\begin{array}{l}\text { Median age } \\
\text { (range) }\end{array}\end{array}$ & 137 & 25 & 15.8 & 9.5 \\
$\begin{array}{l}\text { Median density } \\
\left.\text { (eosinophils } / \mathrm{mm}^{2}\right)\end{array}$ & 653 & 15.5 & 25 & 31.4 \\
$\begin{array}{l}\text { Mean density } \\
\left.\text { (eosinophils } / \mathrm{mm}^{2}\right)\end{array}$ & 418 & 16.8 & 32.6 & 44.4 \\
$\quad \begin{array}{l}\text { SD } \\
\text { Range }\end{array}$ & $127-2108$ & $0-110$ & $0-219$ & $0-203$ \\
\hline
\end{tabular}

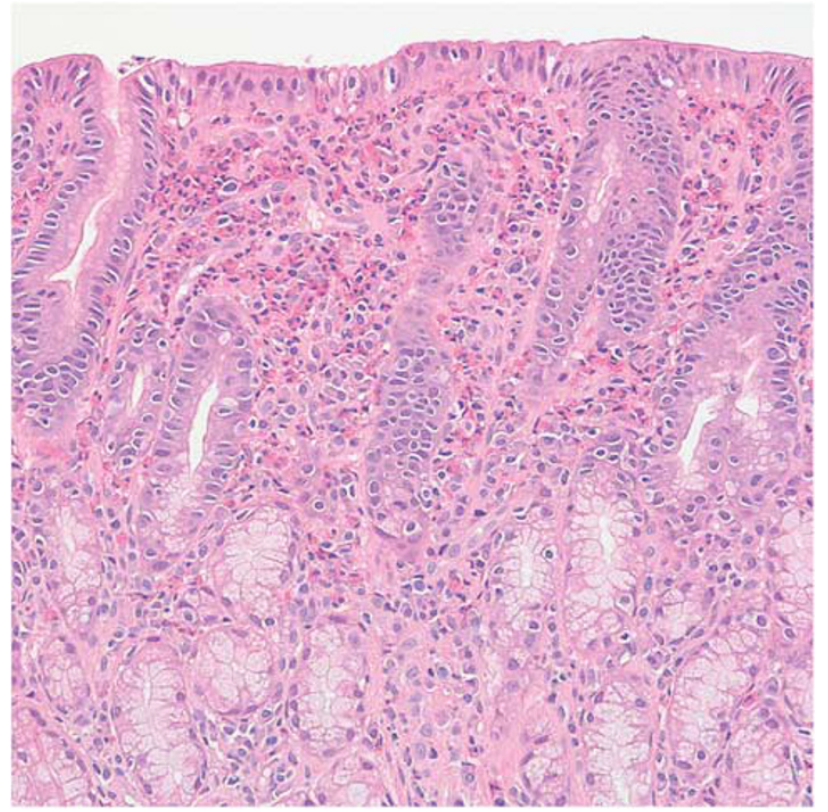

Figure 1 Antral biopsy with marked eosinophilic infiltration within the lamina propria (Hematoxylin and eosin, original magnification $200 \times$ ).

histologically normal, DeBrosse et $a l^{7}$ found peak eosinophil counts of 8 per HPF in antral and 11 per HPF in oxyntic mucosal biopsies. These studies did not report the area of the HPF used for the counts. Several years ago, a small multicenter study suggested that there exist significant variations in colonic mucosa eosinophil counts in different United States cities, eg, between residents of Boston and New Orleans. ${ }^{17}$ To account for as many of these variables as possible, we counted the tissue eosinophils in two to three controls matched for age, sex, and ZIP code, who had gastric biopsies diagnosed as unremarkable. Our results are in agreement with those of Tally and DeBrosse. ${ }^{7,9}$ The mean $( \pm S D$ ) eosinophilic count in 135 subjects with normal gastric mucosa was $15.5 \pm 16.8$ eosinophils $/ \mathrm{mm}^{2}$, and the peak density was around 50 eosinophils/ $\mathrm{mm}^{2}$. Only a single normal control subject had counts that exceeded this value. Also, we found no significant differences related to sex, age, or area of 


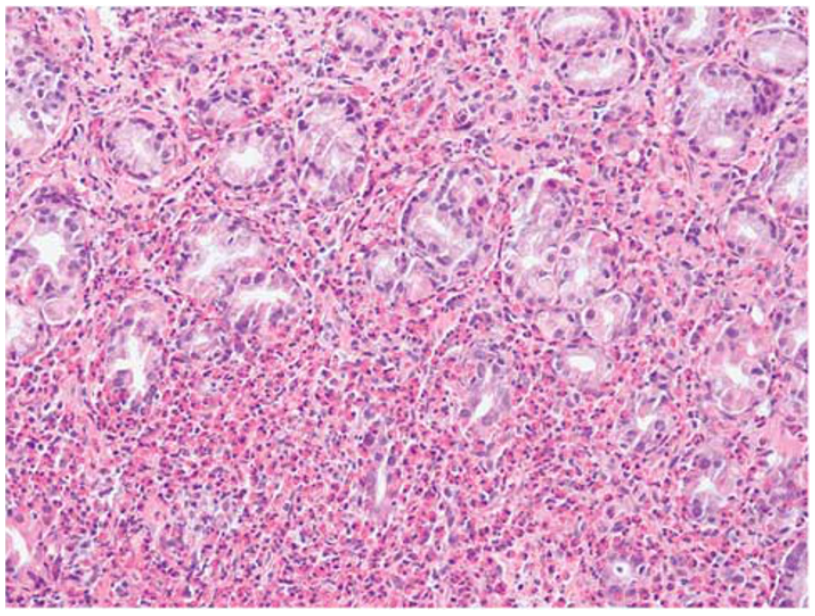

Figure 2 Sheets of eosinophils distort the gastric gland architecture (hematoxylin and eosin, original magnification $200 \times$ ).

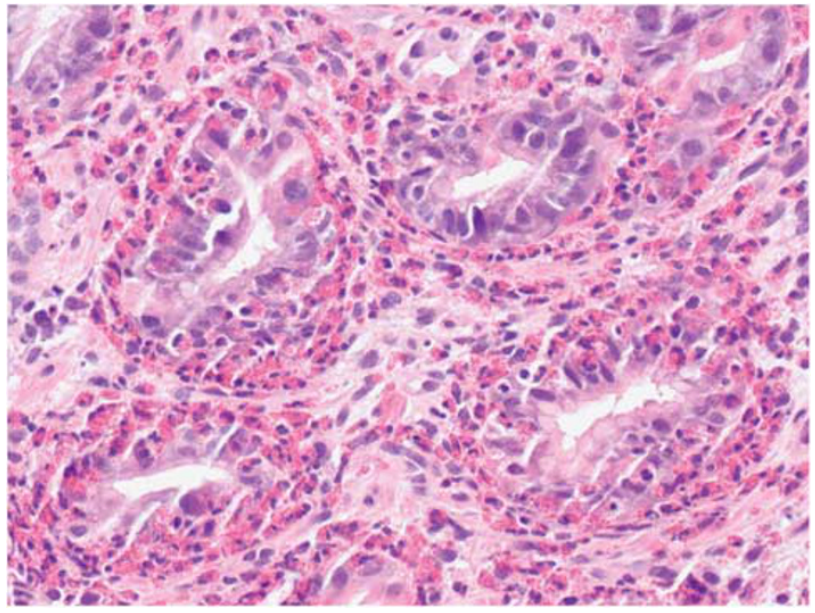

Figure 4 Eosinophils surround and infiltrate the gastric glands, but do not spill into the lumen to form eosinophilic 'pit abscesses' (hematoxylin and eosin, original magnification $400 \times$ ).

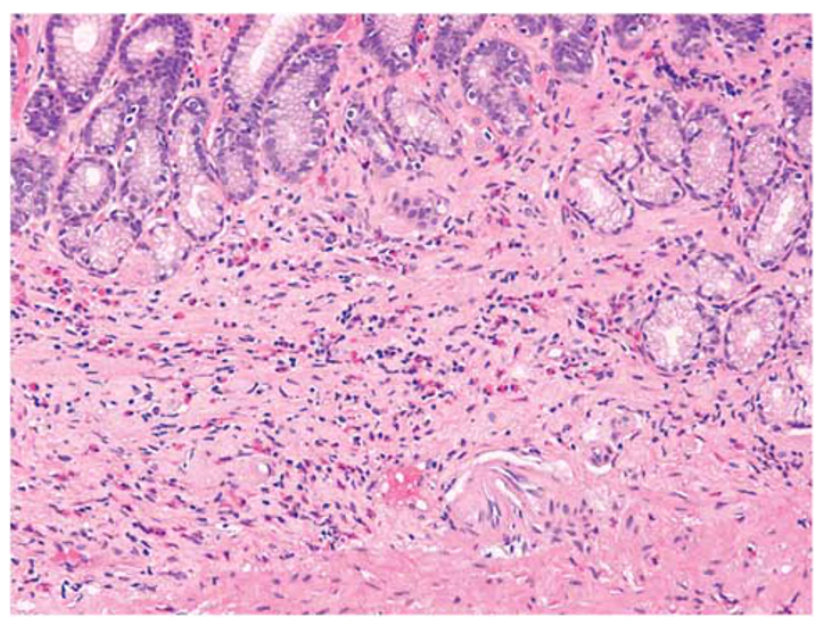

Figure 5 Muscularis mucosae and submucosal tissue involvement by the eosinophilic infiltrate (hematoxylin and eosin, original magnification $200 \times$ ).

two groups there were a few patients with high counts (up to 203-219 eosinophils $/ \mathrm{mm}^{2}$, respectively). Eosinophilic gastritis would be an unlikely consideration in patients with $H$. pylori infection. However, in patients with moderately high eosinophil counts in their gastric mucosa, the possibility of Crohn's disease should be entertained and the relevant clinical history should be obtained.

The next step was to determine a sensible threshold above which eosinophilic gastritis could be considered. The mean count $( \pm S D)$ in our study patients was $653 \pm 418$ eosinophils $/ \mathrm{mm}^{2}$. Only two children (aged 4 and 8 years) with increased gastric eosinophils had $<190$ eosinophils $/ \mathrm{mm}^{2}$ (127 and 168, respectively). All other patients had counts of 190 eosinophils $/ \mathrm{mm}^{2}$ or higher, with a median of 539 eosinophils $/ \mathrm{mm}^{2}$ and a mode of 463 eosinophils/ $\mathrm{mm}^{2}$. One could argue that a likely reason why no study patient had fewer than 127 eosinophils $/ \mathrm{mm}^{2}$

Crohn's disease had mucosal eosinophilic counts similar to our normal controls, but in each of these 


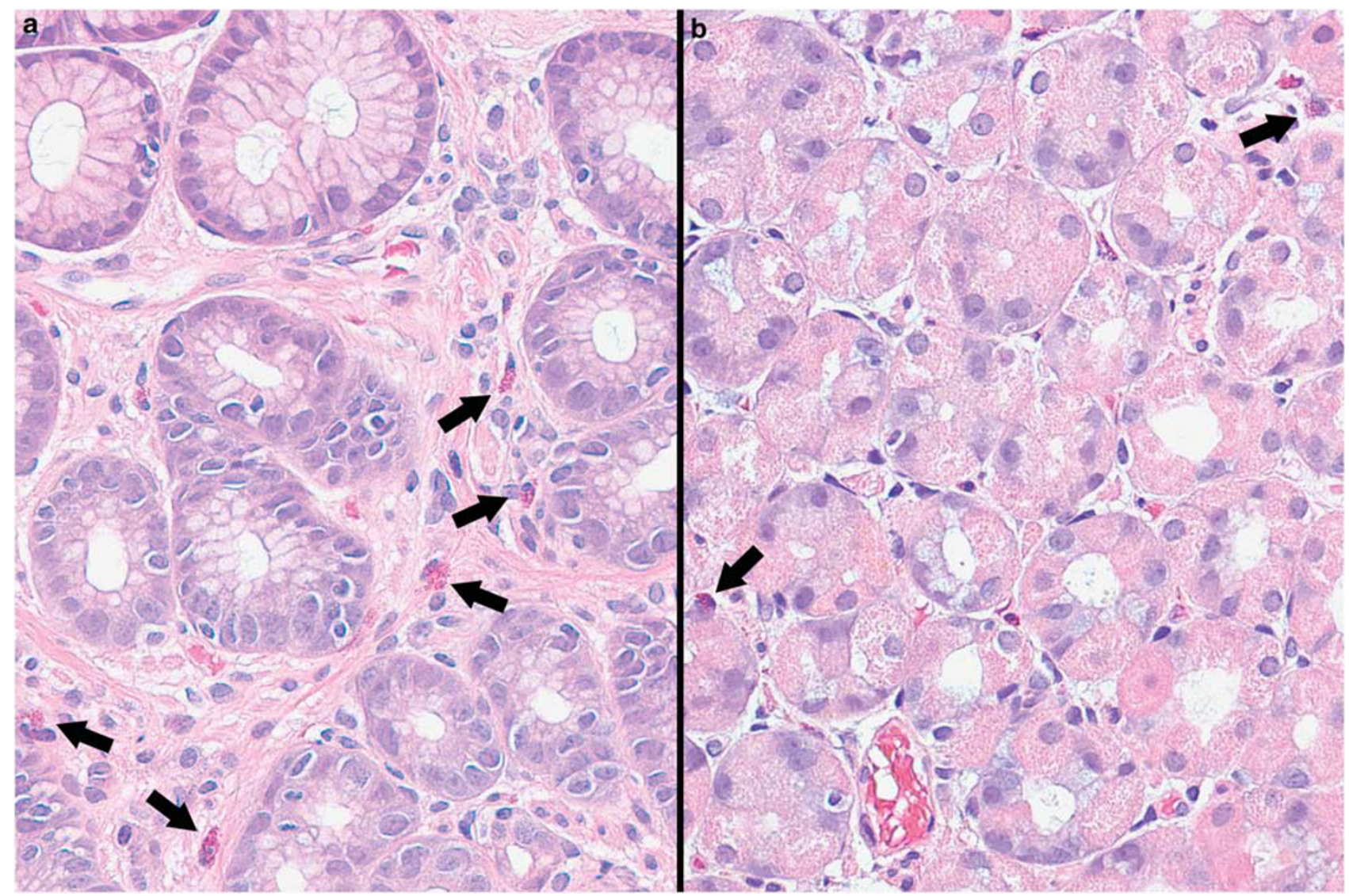

Figure 6 Antral (a) and corpus (b) biopsy from a normal control. There are five or fewer eosinophils per high-power field in the lamina propria, and there are no eosinophils within the epithelium (hematoxylin and eosin, original magnification $600 \times$ ).

(or 30 per HPF) was because pathologists tend not to report tissue eosinophilia below such threshold. However, the fact that only one of 135 controls whose biopsies had been diagnosed as normal had more that 54 eosinophils $/ \mathrm{mm}^{2}$ supports the contention that elevated gastric eosinophilic counts in the general population are indeed extremely rare.

During the 2 years covered in this study, 2525 unique patients with both esophageal and gastric biopsies examined in our laboratory, and had a histological diagnosis consistent with eosinophilic esophagitis (ie, >15 eosinophils per HPF in the esophageal squamous mucosa, eosinophil degranulation, microabscesses, and other compatible epithelial features). ${ }^{19}$ However, the prevalence of gastric involvement in these patients was $<0.6 \%$. Only 14 of these patients (all reported in this series) had also significant eosinophilic infiltrates in the stomach. None of the control patients' esophageal biopsies demonstrated increased eosinophils. This low prevalence suggests that these two conditions are likely not related. Two study patients also had an eosinophilic infiltrate in the duodenum; such cases could be classified as eosinophilic gastroenteritis. ${ }^{20}$ Furthermore, our data are in agreement with a recent article reporting on the rarity of eosinophilic gastroenteritis. ${ }^{21}$
The term secondary eosinophilic gastritis, rarely used outside the context of classifications, implies that the reasons for the eosinophilic infiltrates in the gastric mucosa are known. These may include infection with Anisakis spp., ${ }^{13}$ Strongyloides stercoralis, ${ }^{22}$ H. pylori ${ }^{23}$ infections, ${ }^{24,25}$ after $H$. pylori treatment, ${ }^{11}$ drugs, ${ }^{12}$ connective tissue diseases, hematopoietic disorders, and food allergy. It must be emphasized, however, that with the exception of tissue eosinophilia associated with nematode larvae, connective tissue diseases, and hematopoietic disorders, all other associations are putative, based solely on individual case reports or small series. In our series, we could not document a specific etiology for the gastric eosinophilia in any of the patients. In one case, the referring clinician emphasized the use of meloxicam by patient as a cause for erosive gastritis, and the reporting pathologist indicated that as a possible cause for eosinophilia. However, there are only rare reports eosinophilic infiltrates associated with this drug, all limited to the lungs. ${ }^{26}$

Primary eosinophilic gastritis may be found in association with a generalized infiltration of eosinophils in other segments of the digestive tract; it is also referred to as idiopathic or allergic gastroenteritis and is typically considered a pediatric condition. ${ }^{14,27}$ However, our data suggest that isolated 
histological eosinophilic gastritis exists in both children and adults.

The clinical information available to us was somewhat limited and we had no access to relevant laboratory data, such as peripheral eosinophil counts and serum IgE immunoglobulin levels. This limitation, in addition to the wide variety of nonspecific presenting signs and symptoms reported by our patients and the lack of distinctive endoscopic characteristics, makes it premature to propose integrated clinicopathological criteria to define eosinophilic gastritis as a new entity. However, on the basis of impressive histopathological findings demonstrated in this series, we recommend that the term 'histological eosinophilic gastritis' be used for the diagnosis in patients who: (1) have gastric biopsies that show an average density $\geq 127$ eosinophils $/ \mathrm{mm}^{2}$ (or $\geq 30$ eosinophils per HPF on microscopes equipped with wide-lens oculars) in at least five separate HPFs; and (2) have no known associated causes of eosinophilia (eg, H. pylori infection, Crohn's disease, parasitic infections, and hematological or lymphoid disorders). If regularly reported, it may become possible to analyze clinicopathological information from a sufficient number of patients and detect common features, which in turn will help generate testable etiological hypotheses.

\section{Disclosure/conflict of interest}

Thida Lwin and Robert Genta are employees of Caris Life Sciences. Shelby Melton has no financial interest to declare.

\section{References}

1 Ayyub M, Almenawi L, Mogharbel MH. Eosinophilic gastritis; an unusual and overlooked cause of chronic abdominal pain. J Ayub Med Coll Abbottabad 2007; 19:127-130.

2 Chaudhary R, Shrivastava RK, Mukhopadhyay HG, et al. Eosinophilic gastritis-an unusual cause of gastric outlet obstruction. Indian J Gastroenterol 2001;20:110.

3 Copeland $\mathrm{BH}$, Aramide OO, Wehbe SA, et al. Eosinophilia in a patient with cyclical vomiting: a case report. Clin Mol Allergy 2004;2:7.

4 Ormeci N, Bayramoglu F, Tulunay O, et al. Cancer-like eosinophilic gastritis. Endoscopy 1994;26:509.

5 Pausawasdi A, Thongprasroeth S, Viranuvatti V, et al. Diffuse eosinophilic gastritis. J Med Assoc Thai 1982;65:151-157.

6 Lash RH, Lauwers GY, Odze RD, et al. Inflammatory Disorders of the Stomach. In: Odze RD and Goldblum JR (eds). Surgical Pathology of the GI TRact, Liver, Biliary Tract, and Pancreas, 2nd edn. Sunders Elsevier: Philadelphia, 2009, pp 269-320.

7 DeBrosse CW, Case JW, Putnam PE, et al. Quantity and distribution of eosinophils in the gastrointestinal tract of children. Pediatr Dev Pathol 2006;9: 210-218.
8 Lowichik A, Weinberg AG. A quantitative evaluation of mucosal eosinophils in the pediatric gastrointestinal tract. Mod Pathol 1996;9:110-114.

9 Talley NJ, Walker MM, Aro P, et al. Non-ulcer dyspepsia and duodenal eosinophilia: an adult endoscopic population-based case-control study. Clin Gastroenterol Hepatol 2007;5:1175-1183.

10 Dixon MF, Genta RM, Yardley JH, et al. Classification and Grading of Gastritis. In: Graham DY, Genta RM, and Dixon MF (eds). Gastritis. Lippincott Williams \& Wilkins: Philadelphia, 1999, pp 35-49.

11 Genta RM, Lew GM, Graham DY. Changes in the gastric mucosa following eradication of Helicobacter pylori. Mod Pathol 1993;6:281-289.

12 Pusztaszeri MP, Genta RM, Cryer BL. Drug-induced injury in the gastrointestinal tract: clinical and pathologic considerations. Nat Clin Pract Gastroenterol Hepatol 2007;4:442-453.

13 Muraoka A, Suehiro I, Fujii M, et al. Acute gastric anisakiasis: 28 cases during the last 10 years. Dig Dis Sci 1996;41:2362-2365.

14 Khan S, Orenstein SR. Eosinophilic gastroenteritis: epidemiology, diagnosis and management. Paediatr Drugs 2002;4:563-570.

15 Sheikh RA, Prindiville TP, Pecha RE, et al. Unusual presentations of eosinophilic gastroenteritis: case series and review of literature. World J Gastroenterol 2009;15:2156-2161.

16 Collins $\mathrm{MH}$. Histopathology associated with eosinophilic gastrointestinal diseases. Immunol Allergy Clin North Am 2009;29:109-117 x-xi.

17 Pascal RR, Gramlich TL, Parker KM, et al. Geographic variations in eosinophil concentration in normal colonic mucosa. Mod Pathol 1997;10:363-365.

18 Polydorides AD, Banner BF, Hannaway PJ, et al. Evaluation of site-specific and seasonal variation in colonic mucosal eosinophils. Hum Pathol 2008;39:832-836.

19 Furuta GT, Liacouras CA, Collins MH, et al. Eosinophilic esophagitis in children and adults: a systematic review and consensus recommendations for diagnosis and treatment. Gastroenterology 2007;133:1342-1363.

20 Ammoury RF, Rosenman MB, Roettcher D, et al. Incidental gastric eosinophils in patients with eosinophilic esophagitis: do they matter? J Pediatr Gastroenterol Nutr 2010;51: 723-726.

21 Chang JY, Choung RS, Lee RM, et al. A shift in the clinical spectrum of eosinophilic gastroenteritis toward the mucosal disease type. Clin Gastroenterol Hepatol 2010;8:669-675.

22 Rivasi F, Pampiglione S, Boldorini R, et al. Histopathology of gastric and duodenal strongyloides stercoralis locations in fifteen immunocompromised subjects. Arch Pathol Lab Med 2006;130:1792-1798.

23 Papadopoulos AA, Tzathas C, Polymeros D, et al. Symptomatic eosinophilic gastritis cured with Helicobacter pylori eradication. Gut 2005;54:1822.

24 Johnstone JM, Morson BC. Eosinophilic gastroenteritis. Histopathology 1978;2:335-348.

25 Takeyama J, Abukawa D, Miura K. Eosinophilic gastroenteritis with cytomegalovirus infection in an immunocompetent child. World J Gastroenterol 2007;13:4653-4654.

26 Karakatsani A, Chroneou A, Koulouris NG, et al. Meloxicam-induced pulmonary infiltrates with eosinophilia: a case report. Rheumatology (Oxford) 2003; 42:1112-1113.

27 Yan BM, Shaffer EA. Primary eosinophilic disorders of the gastrointestinal tract. Gut 2009;58:721-732. 